\title{
Kearifan Lokal (Ruwat Petirtaan Jolotundo) dalam Menjaga Kelestarian Lingkungan Hidup
}

\author{
Alif Putra Lestari, Sri Murtini, Bambang Sigit Widodo, Nugroho Hari \\ Purnomo
}

Masuk: 24012021 / Diterima: 21052021 / Dipublikasi: 30062021

\begin{abstract}
Indonesia's natural wealth must be maintained as a source of human life. However, currently, there is much environmental damage in Indonesia due to human activity. The environment that provides livelihoods is a threat to the community because of its damage. Several local community groups are continuing to strive to protect their environment, one of which is through local wisdom. This study aims to determine how the impact of the local wisdom of Ruwat Petirtaan Jolotundo on the preservation of the environment around it. This study uses a qualitative approach with in-depth interview techniques, participatory observation, and documentation. This research was conducted in Seloliman Village, Trawas, Mojokerto. The research was conducted for six months, starting from preparation, preliminary studies, interviews, observations, and participating in Ruwat activities to data processing and analysis. The results showed that Ruwat Petirtaan Jolotundo had a good impact on preserving water sources, flora, and fauna in the Jolotundo area. The quantity and quality of water sources are maintained. Pine, mahogany, sengon, teak, and fauna such as monkeys, wild dogs, and wild boar (wild boar) can easily be found. Ruwat Jolotundo can make people aware of the importance of protecting the environment. This local wisdom must be preserved and passed on to our children and grandchildren as the nation's successor to maintain our environment. This research can be developed on the theme of the urgency of Ruwat or local wisdom as an alternative to protecting the environment.
\end{abstract}

Key words: Local Wisdom; Ruwat Jolotundo; Sustainable Environment

\begin{abstract}
Abstrak Kekayaan alam Indonesia harus dijaga keberadaannya sebagai sumber kehidupan manusia. Tetapi saat ini banyak terjadi kerusakan lingkungan hidup di Indonesia akibat ulah manusia. Lingkungan hidup yang memberikan penghidupan justru menjadi ancaman untuk masyarakat karena kerusakannya. Beberapa kelompok masyarakat daerah ada yang terus berupaya menjaga lingkungan hidup mereka, salah satunya melalui kearifan lokal. Penelitian ini bertujuan untuk mengetahui bagaimana dampak kearifan lokal Ruwat Petirtaan Jolotundo pada kelestarian lingkungan hidup di sekitarnya. Penelitian ini menggunakan pendekatan kualitatif dengan teknik wawancara mendalam, observasi partisipasi, dan dokumentasi. Penelitian ini dilaksanakan di Desa Seloliman Kecamatan Trawas Kabupaten Mojokerto. Penelitian dilaksanakan selama 6 bulan, diawali dari persiapan, studi pendahuluan, wawancara, observasi serta mengikuti kegiatan Ruwat, hingga pengolahan dan analisis data. Hasil penelitian menunjukkan bahwa Ruwat Petirtaan Jolotundo memberikan dampak yang baik terhadap kelestarian sumber air, flora dan fauna di kawasan Jolotundo. Sumber air sangat terjaga kuantitas dan kualitasnya, tumbuhan pinus, mahoni, sengon, jati dan fauna seperti kera,anjing liar, dan babi hutan (celeng) dengan mudah dapat ditemukan. Ruwat Jolotundo mampu menyadarkan masyarakat akan pentingnya menjaga lingkungan. Kearifan lokal ini harus dijaga dan diturunkan kepada anak cucu sebagai penerus bangsa agar lingkungan kita tetap terjaga. Penelitian ini dapat dikembangkan pada tema urgensi Ruwat atau kearifan lokal sebagai alternatif menjaga lingkungan hidup.
\end{abstract}

Kata kunci : Kearifan Lokal; Ruwat Jolotundo; Pelestarian Lingkungan

This is an open access article under the CC BY-SA license.

Copyright (O 2021 by Author. Published by Universitas Pendidikan Ganesha.

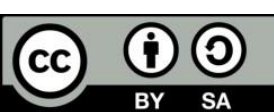




\section{Pendahuluan}

Indonesia menjadi salah satu negara dengan kekayaan alam yang besar di dunia. Kekayaan laut, hutan, sungai, pegunungan, hewan, tambang memberikan keuntungan yang tidak dimiliki oleh negara lain. Keberadaan sumber daya alam yang beraneka ragam ini perlu dijaga sebagai upaya menjaga keharmonisan antara manusia dan alam. Manusia perlu menjaga lingkungan hidup dimana mereka tinggal, sebab dari alamlah kebutuhan manusia dapat terpenuhi. Termasuk masyarakat Indonesia yang hidup dengan memanfaatkan kekayaan alam di negeri ini.

Kenyataan di lapangan justru sebaliknya, kerusakan lingkungan semakin hari semakin meluas dan tidak terkendali, kerusakan terjadi di berbagai sektor, baik di darat, di laut, maupun di udara. Aktivitas manusia memberikan dampak buruk terhadap lingkungan, masyarakat semakin tidak peduli dengan lingkungan tempat tinggal mereka. Berdasarkan data yang dirilis Kementerian Lingkungan Hidup dan Kehutanan Republik Indonesia (2018) nilai Indeks Kualitas Air (IKA) nasional turun sebesar 1,70 dan nilai Indeks Kualitas Tutupan Lahan (IKTL) nasional turun sebesar 0,95.

Seperti halnya di Maluku Tenggara, sebagaian besar terumbu karang di perairan Ohoi Ngilngof kondisinya rusak hingga rusak berat, salah satu penyebabnya adalah polusi sedimen dari perusahaan sekitar (Uar

Alif Putra Lestari, Sri Murtini, Bambang Sigit Widodo, Nugroho Hari Purnomo

Universitas Negeri Surabaya, Indonesia

alieflestari8@gmail.com et al., 2016). Serta banyak kejadian kebakaran hutan, pencemaran air sungai, kekeringan, masalah sampah, pencemaran udara, dan lain sebagainya. Catatan dari Badan Pusat Statistik Indonesia (2020) yang didapatkan dari Kementerian Lingkungan Hidup dan Kehutanan pada tahun 2019 dari 98 sungai di Indonesia 54 sungai berstatus cemar ringan, 6 sungai cemar ringan-cemar sedang, dan 38 sungai berstatus cemar ringancemar berat. Kondisi demikian lebih buruk dari tahun 2018, belum lagi laju deforestasi hutan di Indonesia yang terus meningkat.

Tentunya hal ini menjadi sebuah ancaman serta sebuah kerugian bagi keberlangsungan hidup manusia yang sebenarnya punya ketergantungan besar pada alam. Segala aktivitas manusia harusnya mempertimbangkan keberadaan lingkungan di sekitar mereka. Sebab perilaku manusia akan sangat mempengaruhi kondisi alam di sekitarnya (Puspita dkk., 2016). Tetapi dewasa ini modernitas justru membuat alam semakin mengalami penurunan kualitas dan itu membahayakan kehidupan manusia itu sendiri.

Instansi pendidikan ataupun yang berhubungan dengan lingkungan hidup sering memberikan himbauan kepada masyarakat untuk menjaga lingkungan. Namun belum optimal karena mereka baru sebatas teori yang susah untuk dibuktikan penerapannya di lapangan. Justru yang giat dalam upaya pelestarian lingkungan adalah orang-orang atau kelompok di daerah atau desa yang mereka hidup berdampingan dengan alam.

Saat di tempat-tempat lain mementingkan pembangunan dan 
mengesampingkan kelestarian alam. Terdapat suatu kelompok masyarakat yang justru teguh dalam menjaga lingkungan hidup, khususnya sumber air di daerah mereka. Tepatnya di Desa Seloliman, Kecamatan Trawas, Kabupaten Mojokerto. Masyarakat disana menjaga dengan baik sumber air Jolotundo melalui kearifan lokal Ruwat. Kearifan lokal ini berupa ritual yang dilaksanakan di kompleks Candi Jolotundo, dengan tujuan mensyukuri rahmat Tuhan berupa air yang terus mengalir dari sumber air yang terdapat di candi Jolotundo (Hartoyo, 2016)

Hal ini menjadi penting dan menarik untuk digali bagaimana sebuah kearifan lokal mempunyai dampak positif terhadap kelestarian lingkungan. Apalagi secara fungsional kearifan lokal sangat berkaitan dengan harmoni, keseimbangan dan keberlanjutan (Kristiyanto, 2017). Hasil penelitian Mas'ud (2019) menyatakan bahwa air Jolotundo sangat sakral bagi masyarakat, karena dianggap suci dan berkhasiat. Belum dibahas terkait dampak positif Ruwat Jolotundo terhadap keberadaan sumber air di sana. Maka pada penelitian bertujuan untuk menggali lebih dalam dampak positif Ruwat Jolotundo terhadap kelestarian lingkungan hidup, khususnya sumber air Jolotundo.

\section{Metode}

Penelitian ini menggunakan pendekatan kualitatif dengan teknik wawancara mendalam, observasi partisipasi, dan dokumentasi. Peneliti melakukan wawancara mendalam untuk mendapatkan informasi tentang pelaksanaan Ruwat dan dampak Ruwat terhadap kelestarian lingkungan.
Wawancara merupakan proses yang penting dalam melaksanakan suatu penelitian khususnya penelitian yang bersifat kualitatif (Rosaliza, 2015). Informan yang diwawancarai adalah Kepala Desa Seloliman, Kepala Dusun Biting, Tokoh Desa, Kepala Adat Kecamatan Trawas, Juru Kunci Jolotundo, serta beberapa warga yang terlibat langsung dengan Ruwat Petirtaan Jolotundo.

Peneliti juga melakukan observasi partisipasi dengan mengikuti serangkaian kegiatan Ruwat Petirtaan Jolotundo yang dilaksanakan pada bulan September 2019, untuk mengetahui secara langsung prosesi Ruwat dari awal hingga akhir. Untuk menggali makna dari Ruwat Petirtaan Jolotundo kaitannya dengan pelestarian lingkungan. Selain itu peneliti juga memperkuat data dengan buku atau tulisan dari penulis lokal terkait pelaksanaan Ruwat serta dampaknya untuk pelestarian lingkungan. Urutan penelitian ini adalah menetapkan informan, melakukan wawancara, membuat catatan, analisis wawancara, dan membuat kesimpulan.

Penelitian ini dilaksanakan di

Desa Seloliman Kecamatan Trawas Kabupaten Mojokerto. Penelitian dilaksanakan selama 4 bulan, diawali dari persiapan, studi pendahuluan, wawancara, dokumentasi hingga mengikuti kegiatan Ruwat, hingga pengolahan dan analisis data. Instrumen penelitian yang digunakan memuat 2 hal yaitu penjelasan tentang pelaksanaan Ruwat jolotundo dan dampaknya terhadap kelestarian lingkungan. Fokus penelitian sesuai dengan rumusan masalah yaitu dampak kearifan lokal Ruwat Petirtaan 
Jolotundo terhadap kelestarian lingkungan terutama keberadaan sumber mata air, kelestarian flora dan fauna. Sedangkan analisis data dilakukan sejak sebelum penelitian, saat penelitian dan setelah penelitian. Kemudian data yang diperoleh akan direduksi untuk menajamkan data, disajikan, dan ditarik sebuah kesimpulan.

\section{Hasil dan Pembahasan}

Selain Ruwat Petirtaan Jolotundo, masih banyak lagi kearifan lokal di Mojokerto, tetapi pada penelitian ini hanya mengkaji Ruwat karena kaitannya dengan pelestarian lingkungan. Menurut Daniah (2018) kearifan lokal sebagai kebijakan yang bersandar pada filosofi, nilai-nilai, etika, dan perilaku yang melembaga secara tradisional untuk mengelola sumber daya (alam, manusia, dan budaya) secara berkelanjutan. Kearifan lokal juga diartikan sebagai pandangan hidup dan pengetahuan serta strategistrategi kehidupan masyarakat yang diwujudkan dalam bentuk aktivitas sebagai bentuk respon dalam menghadapi masalah di dalam kehidupan sehari-hari mereka.

Selaras dengan pernyataan Syarif (2017) bahwa saling menghormati bukan hanya kepada sesama manusia tetapi lingkungan juga harus tetap dijaga kelestariannya. Selain itu, permasalahan lingkungan tidak hanya dipecahkan dengan teknologi dan metode ilmiah saja akan tetapi juga perlu dibantu dengan kekuatan-kekuatan lain yaitu religius (agama), kepercayaan, dan etika manusia terhadap alam (Maridi, 2015).
Secara administratif, Petirtaan Jolotundo terletak di Dusun Biting Desa Seloliman Kecamatan Trawas Kabupaten Mojokerto. Desa Seloliman tempat keberadaan Petirtaan Jolotundo mempunyai luas wilayah 4,62 km² (BPS Kabupaten Mojokerto, 2018). Secara umum tanah yang berkembang di sekitar Petirtaan Jolotundo adalah tanah andosol yang ditandai dengan vegetasi yang lebat dan rapat. Sedangkan jika dilihat secara lebih luas lagi yaitu di Kecamatan Trawas, sebagian besar tanahnya berjenis mediteran, sebagian lagi litosol, dan hanya sedikit saja yang berjenis tanah andosol yaitu di bagian selatan Kecamatan Trawas.

Penduduk sekitar Petirtaan Jolotundo adalah masyarakat Jawa pedesaan yang sebagian masih memegang teguh ajaran leluhur tentang alam sekitar. Menurut Surata dkk. (2015) upaya melestarikan kearifan lokal yang bernilai luhur merupakan kewajiban kita semua. Mereka sangat menjaga sumbersumber mata air yang terdapat di area Jolotundo dan sekitarnya yang merupakan sumber kehidupan mereka. Seperti kearifan komunitas di Bantul yang secara bersama menjaga keberadaan air untuk irigasi sawah (Hariadi dkk., 2020). Masyarakat Seloliman mempunyai tradisi menjaga keberadaan sumber mata air melalui Ruwat Petirtaan Jolotundo sebagai ungkapan rasa syukur mereka. Seperti halnya nilai-nilai ekologi dalam budaya lokal Manggarai yang memiliki ritualritual bermakna simbolik dan mengandung nilai-nilai ekologis yang merupakan bentuk penyatuan yang 
Kearifan Lokal (Ruwat Petirtaan Jolotundo) dalam Menjaga Kelestarian Lingkungan Hidup/Alif Putra Lestari, Sri Murtini, Bambang Sigit Widodo, Nugroho Hari Purnomo

harmonis dan selaras dengan alam (Niman, 2019).

Ruwat Jolotundo merupakan sebuah ritual yang dilaksanakan di kompleks Candi Jolotundo sebagai peninggalan Airlangga yang terdapat beberapa sumber air di dalamnya. Ruwat Jolotundo menjadi agenda wajib setiap tahunnya, seperti halnya upacara Tumpek (menjaga keharmonisan dengan alam lingkungan) di Bali yang dilakukan setiap enam bulan sekali (Sudarsana, 2017). Menurut Mbah Jari (Pemimpin Ruwat Jolotundo) jika ruwatan tidak dilaksanakan, maka sumber air yang ada di Jolotundo akan mengering atau tidak keluar. Adapun upaya-upaya yang dapat dilakukan oleh manusia untuk melestarikan lingkungan, salah satunya dengan tetap mempercayai mitos sebagai salah satu kearifan lokal yang dapat menuntun manusia dapat bersikap arif dan bijaksana (Anggraini, 2018).

Hal demikian didukung dengan temuan Schwann (2018) bahwa penduduk Okanagan haruslah memegang kearifan lokal setempat untuk beradaptasi dengan perubahan alam. Sementara itu sumber air Jolotundo menjadi sumber kehidupan pokok warga Desa Seloliman dan sekitarnya, sehingga Ruwat menjadi bagian hidup mereka. Sebagaimana yang diungkapkan Nasution (2018) kearifan lokal Wasee Glee oleh masyarakat Gampong Alue Bieng dianggap sebagai bagian hidup mereka dalam rangka mengelola hutan. Tidak hanya berdoa saja, selain itu juga digelar kesenian lokal selama Ruwat Jolotundo dilaksanakan seperti
Tandakan, Bantengan, Pecutan, Gong dan lain sebagainya.

Ruwat Petirtaan Jolotundo dalam prosesinya dibagi menjadi 3 tahap, yaitu tahap persiapan, tahap pelaksanaan, dan tahap setelah pelaksanaan. Tahap persiapan dimulai dari persiapan panitia, menyiapkan segala kebutuhan untuk Ruwat, melakukan woro-woro, dan lainnya. Tahap pelaksanaan ada beberapa proses penting di dalamnya yaitu, Sumaningah (memberitahukan), Manunggaling Tirta (menyatukan air), Sumaningah penanaman pohon, Sumaningah pelepasan burung, sambutan, dan Sumaningah ujub tumpeng (doa Jawa). Rangkaian kegiatan Ruwat memiliki makna yang sangat mendalam terhadap sumberdaya air Jolotundo. Menurut Suyatman (2018) nilai-nilai moral dan religius serta etika sering memberikan petunjuk yang sangat berharga bagi perlindungan dan pelestarian lingkungan hidup. Sementara untuk tahap setelah pelaksanaan didominasi acara-acara kebudayaan seperti Beksan, wayang, bantengan, ujung, serta dialog budaya.

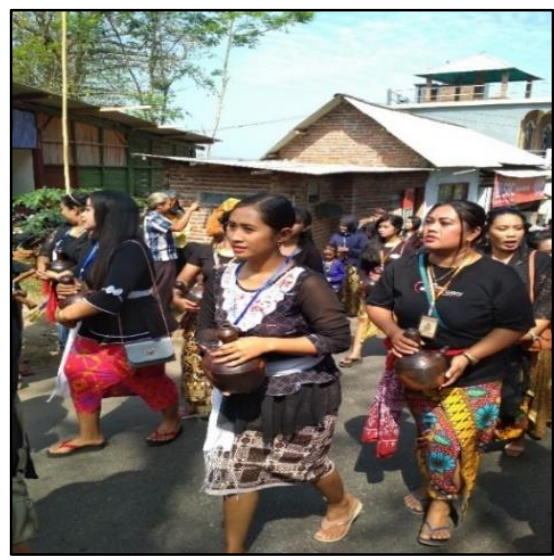

Gambar 1. Prosesi Ruwat Petirtaan Jolotundo 
Gambar di atas merupakan salah satu prosesi dalam serangkaian ritual Ruwat Petirtaan Jolotundo. Rangkaian ritual Ruwat yang telah dilaksanakan sejak dulu dan memberikan dampak yang baik terhadap kelestarian alam sekitar. Sebab selama prosesi ritual masyarakat diajak untuk sadar dan terus menjaga sumber air, dan setelah Ruwat mereka juga harus menjaga flora dan fauna yang ada.

Ruwat Petirtaan Jolotundo memberikan dampak positif terhadap lingkungan sekitar. Terjaganya sumber air hingga saat ini, terjaganya vegetasi, terjaganya hewan di kawasan Jolotundo merupakan dampak langsung dari kegiatan Ruwat.

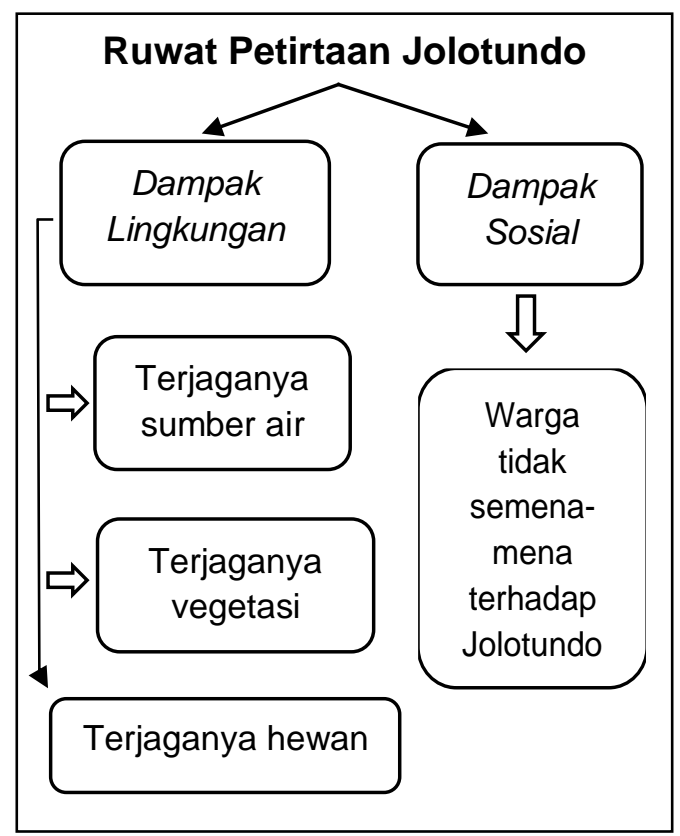

Gambar 2. Kenampakan vegetasi di kawasan Jolotundo

Gambar di atas menjelaskan bahwa selain dampak lingkungan, Ruwat juga memberikan dampak sosial terhadap warga di sekitarnya. Warga Seloliman dan sekitarnya tidak berani bertindak semena-mena terhadap sumber air di Jolotundo.

Kondisi sumber air di Jolotundo masih sangat terjaga dengan baik, secara kualitas dan kuantitas. Air terus mengalir dan memberikan kehidupan untuk manusia, hewan, dan tumbuhan di sekitarnya. Meskipun terjadi musim kemarau yang panjang, tapi hal tersebut tidak berpengaruh secara signifikan terhadap air yang dikeluarkan dari sumber. Ruwat Jolotundo memberikan dampak besar dalam memperkuat rasa syukur masyarakat akan sumber air serta meningkatkan kesadaran akan pentingnya menjaga sumber Jolotundo.

Gatot Hartoyo (Ketua adat Trawas) menyatakan bahwa Ruwat Jolotundo membuat air dari sumber terus mengalir dan tidak pernah kering. Seperti hasil penelitian Sufia dkk. (2016) di Desa Kemiren, Banyuwangi menyebutkan kearifan lokal dalam bentuk kepercayaan terhadap kompleks situs makam Buyut Cili telah menjadikan lingkungan tersebut tetap terjaga keasliannya. Masyarakat Desa Seloliman pun sangat menjaga Jolotundo serta melaksanakan Ruwat karena mereka masih memegang teguh peninggalan nenek moyangnya, adat isitiadat di Desa Seloliman masih kuat. Dharmawibawa (2019) menyatakan bahwa kearifan lokal yang terus dijalankan di Desa Seloto memberikan dampak baik terhadap kelestarian Danau Lebo.

Hasil penelitian Pratiknyo (2016) menunjukkan bahwa Sumber Jolotundo yang terdapat di Desa Seloliman dengan ketinggian 557 mdpl mempunyai debit sumber 0,38 liter/detik pada sumber 1 , sedangkan 
pada sumber 2 mempunyai debit 0,12 liter/detik. Sedangkan dari segi kualitas air tanah pada mata air Jolotundo mempunyai karakteristik sebagai berikut ; 1) warna airnya jernih, 2) tidak berbau, 3) tidak berasa, 4) tingkat kekeruhan pada kondisi jernih, 5) mempunyai suhu $\left.25^{\circ} \mathrm{C}, 6\right)$ derajat keasaman $(\mathrm{pH}) \quad 7,2$ dan 7$)$ residu terlarut 40 ppt. Karakteristik tersebut menjadikan air Sumber Jolotundo sebagai air dengan kualitas yang sangat baik untuk dikonsumsi, untuk diminum sesuai dengan prasyarat air minum.

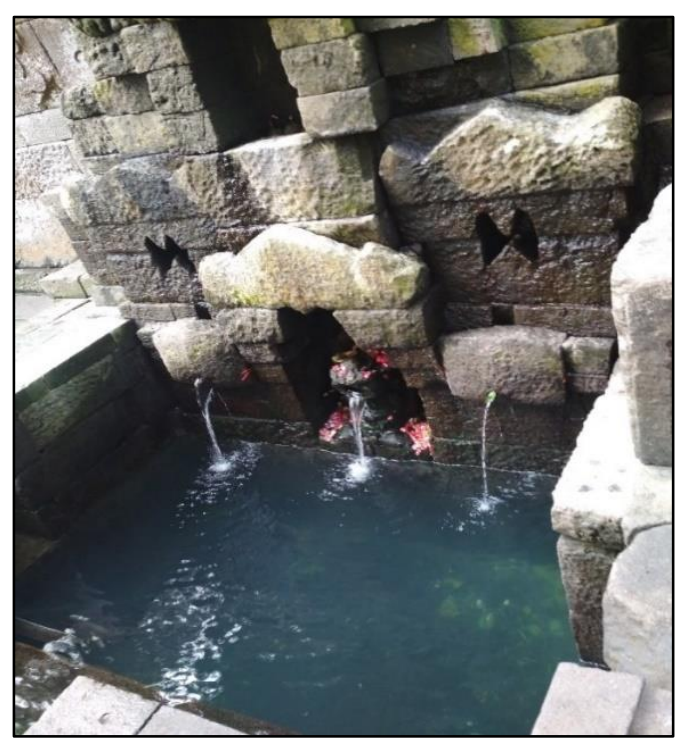

Gambar 3. Salah satu sumber air di Jolotundo

Gambar di atas merupakan salah satu sumber di dalam Jolotundo yang terlihat tidak berwarna dan dapat langsung diminum. Beberapa warga juga menyatakan bahwa dengan rutinnya pelaksanaan Ruwat membuat air dari sumber Jolotundo terjaga kemurniannya.

Setelah prosesi Manunggaling Tirta, terdapat prosesi Sumaningah penanaman pohon. Salah satu rangkaian kegiatan Ruwat dengan menanam pohon secara bersama untuk menambah vegetasi yang ada serta menjaga alam sekitar agar tidak gersang dan gundul. Prosesi ini memunculkan kesadaran masyarakat akan pentingnya menjaga tumbuhan atau hutan di sekitar mereka. Seprianto dkk. (2019) menyatakan bahwa dengan adanya kepercayaan Bukit Larangan yang dipandang sebagai tempat sakral yang tidak boleh disentuh dan dimasuki oleh masyarakat membuat sumber daya hutan dimanfatkan secara kolektif, dianggap sebagai milik bersama. Serta tidak dimonopoli secara individu dan kelompok, sehingga kerusakan lingkungan berkurang di sekitar kawasan Desa Aur Gading.

Bahkan di India beberapa hutan dianggap suci oleh beberapa suku, sehingga hutan tetap terjaga kelestariaannya untuk kehidupan manusia (Kakoty, 2018). Apalagi dalam acara Ruwat juga diikuti oleh anak kecil hingga dewasa dan tua, yang secara tidak langsung Ruwat menjadi sarana pembelajaran bagi mereka. Sehingga ketika setelah Ruwat masyarakat mampu melanjutkan budaya menjaga vegetasi. Bagi masyarakat Jawa, lingkungan adalah manifestasi anugerah dari Sang Pencipta, oleh karena itu lingkungan harus dijaga (Mardikantoro, 2016). Sebab dengan terjaganya vegetasi maka akan berpengaruh baik pada sumber air di Jolotundo, penyerapan air oleh tumbuhan akan menjaga keseimbangan.

Hasilnya adalah tumbuhtumbuhan alami di sekitar kawasan Petirtaan Jolotundo masih sangat 
Kearifan Lokal (Ruwat Petirtaan Jolotundo) dalam Menjaga Kelestarian Lingkungan Hidup/Alif Putra Lestari, Sri Murtini, Bambang Sigit Widodo, Nugroho Hari Purnomo

terjaga hingga saat ini. Pohon besar tumbuh dengan kerapatan tinggi, rumput serta bambu. Serta banyak pohon buah-buahan yang masih terjaga keberadaannya. Pohon jati, mahoni, sono, dan sengon, serta pohon-pohon khas yang mungkin sebagian tidak ditemui di hutan lain masih terjaga keberadaannya. Pohon-pohon tersebut tumbuh menyebar di hutan-hutan (hutan lindung, hutan produksi) dan tegalan.

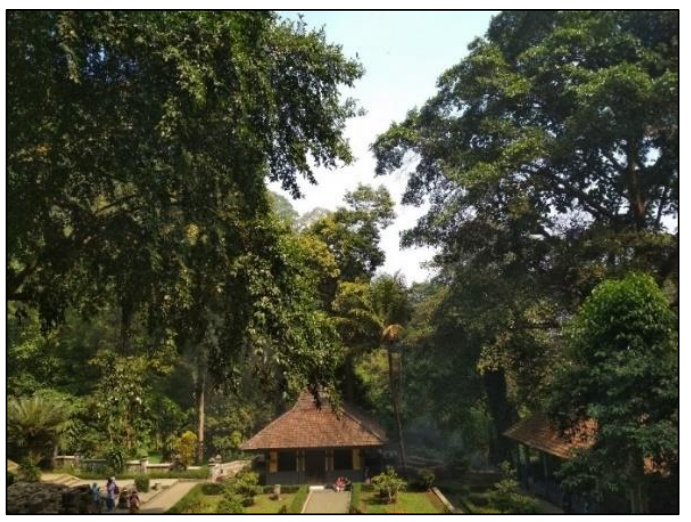

Gambar 4. Kenampakan vegetasi di kawasan Jolotundo

Gambar di atas menunjukkan kondisi vegetasi yang berada di dalam kompleks Petirtaan Jolotundo yang asri dan terjaga. Begitu pula kondisi di luar kompleks Petirtaan Jolotundo, ataupun hampir di seluruh wilayah Desa Seloliman yang masih sangat terjaga segala jenis tumbuhan yang ada. Secara umum vegetasi di kawasan Jolotundo masih hijau, yang berarti bahwa masih dijaga oleh penduduk sekitar dengan baik. Kesadaran akan pentingnya pohon dari acara Ruwat menjadi salah satu penyebab kondisi flora yang ada. Menurut Swandi (2017) kearifan lokal dalam pengelolahan hutan merupakan warisan leluhur dalam rangka beradaptasi dengan alam.

Selanjutnya dari prosesi Ruwat yang mempunyai dampak positif terhadap lingkungan hidup adalah Sumaningah pelepasan burung. Sebuah ritual melepaskan burung ke alam bebas, sebuah pelajaran berharga bagi masyarakat, sebuah kesadaran yang mahal di zaman sekarang. Achal dkk. (2016) menyatakan kita saat ini berada di era dimana keberlanjutan menjadi hal yang sangat penting. Tujuan dari prosesi pelepasan burung adalah agar masyarakat tidak menangkap atau menembak burung sembarangan, masyarakat menjaga segala jenis fauna yang ada di sekitar kawasan Jolotundo.

Sehingga masyarakat akan terbiasa menjaga fauna yang ada, secara tidak langsung mereka juga menjaga sumber air dan flora yang ada sebagai penopang kehidupan fauna. Sebab kearifan lokal berdasar pada kemampuan komprehensif manusia untuk mencapai keharmonisan dengan alam (Zhang dkk., 2016). Seperti halnya adat Sasi yang dilakukan masyarakat Maluku dan Papua adalah agar sumber daya dapat terus menjamin kehidupan generasi mendatang (Putri dkk., 2020).

Hingga saat ini penduduk kawasan Jolotundo dengan mudah dapat menemukan kera, anjing liar, babi hutan (celeng) serta beberapa jenis burung di hutan sekitar Petirtaan Jolotundo. Selaras dengan kondisi vegetasi yang baik, maka fauna yang ada juga mengikuti sebab hutan dan pohon adalah rumah bagi fauna, termasuk sumber makanan di dalamnya. Termasuk juga keberadaan 
sumber air Jolotundo yang memperkuat kehidupan vegetasi, yang secara tidak langsung juga memperkuat kehidupan fauna yang ada. Masyarakat juga terus disadarkan akan pentingnya menjaga fauna melalui Ruwat Jolotundo yang tidak pernah absen digelar. Seperti Tradisi Lombe di Pulau Kangean yang dapat mempengaruhi minat masyarakat dalam memelihara kerbau sehingga Tradisi Lombe menjadi solusi dalam menjaga keberadaan kerbau di Pulau Kangean (Ulum dkk., 2019).

Berawal dari kegiatan Ruwat, dalam kehidupan sehari-hari masyarakat punya kesepakatan bersama yang berupa larangan di sekitar Jolotundo agar tetap terjaga kemurniannya. Seperti penelitian Reza \& Hidayati (2017) bahwa adanya pelarangan/perlindungan dan pemeliharaan untuk mencegah kerusakan dan kemusnahan melalui budaya pamali membuat sumberdaya air bisa dimanfaatkan dengan baik dan berkelanjutan bagi kehidupan masyarakat Desa Lenek Daya. Senada dengan pernyataan Sinapoy (2018) bahwa masyarakat lokal yang mempunyai kearifan tradisional mampu melahirkan kearifan lingkungan yang seiring dan sejalan, serta menjaga kelestarian sumber daya alam. Kesepakatan tersebut berdampak pada terjaganya Sumber Jolotundo sehingga memperlancar pasokan air untuk pertanian desa, sehingga kegiatan pertanian tidak terhambat.

Serangkain kegiatan Ruwat yang berisi banyak prosesi salah satunya berisi wejangan (nasehat) dari para tokoh desa. Mereka terus menceritakan kesakralan Jolotundo beserta sumber air di dalamnya sebagai peninggalan nenek moyang yang harus dijaga. Hal demikian terus ditekankan pada para peserta Ruwat dan masyarakat Desa Seloliman sebagai pengingat yang luhur. Selain itu setiap prosesi yang dilaksanakn menunjukkan penghormatan yang tinggi terhadap Jolotundo, juga terhadap air Jolotundo yang dianggap suci.

Berdasarkan hasil wawancara dengan Pak Sucaj (Juru Kunci Jolotundo) didapatkan beberapa hal tentang Ruwat dan sumber air Jolotundo. Menurut beliau, kegiatan Ruwat yang sakral telah melahirkan beberapa aturan tidak tertulis yang berlaku di Jolotundo di antaranya adalah 1) pengunjung dilarang bertindak asusila dan harus sopan; 2) menjaga adab ketika mandi di Jolotundo; 3) membawa sesaji dan makanan ikan; serta 4) pengunjung tidak naik di tempat ibadah. Seiring dipatuhinya aturan tersebut membuat sumber air di Jolotundo tidak dijamah sembarangan sehingga terjaga kebersihan dan keberadaannya. Kondisi demikian menjadikan sumber air di Jolotundo senantiasa terjaga. Selaras dengan hasil penelitian Mawaddahni (2017) bahwa masyarakat Kasepuhan Sinar Resmi diwajibkan untuk memohon izin, yang diawali dengan doa untuk meminta keberkahan, keselamatan dan keberhasilan saat memetik atau memanen di sawah.

Selain itu beberapa perangkat desa dan tokoh desa yang mengikuti Ruwat mempercayai kesucian air Jolotundo, sehingga mereka juga turut menjaga keberadaan sumber air. Para pengunjung dari luar kota juga meyakini 
kesakralan air Jolotundo sebagaimana yang diceritakan dalam ritual Ruwat. Praktis kearifan lokal sebagai upaya masyarakat untuk melestarikan sumber daya yang dapat digunakan terus menerus untuk memberi makan masyarakat dan menjaga keseimbangan lingkungan (Vitasurya, 2016).

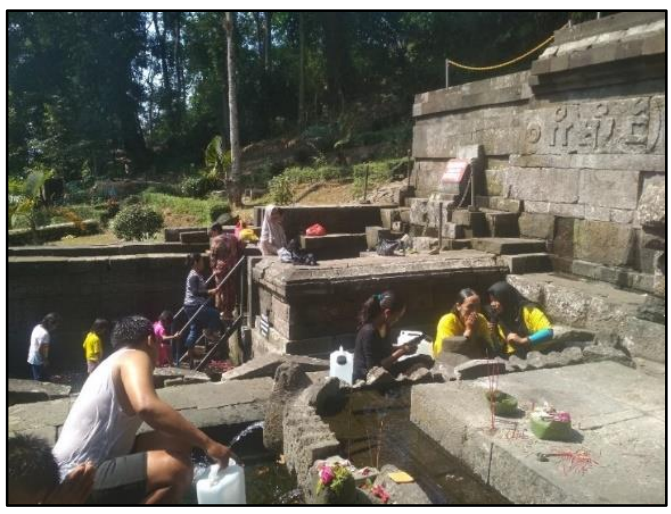

Gambar 5. Warga yang memanfaatkan air dari sumber

Gambar di atas merupakan gambaran warga yang mengambil air di Jolotundo sesuai dengan aturan yang berlaku di dalamnya. Ruwat memberikan dampak besar akan ketidakberanian warga berbuat hal yang dapat merusak sumber air. Mereka sangat menjaga ajaran leluhur yang ditampilkan melalui Ruwat Petirtaan akan sucinya sumber air Jolotundo yang menghidupi mereka. Seperti pernyataan Thamrin (2017) bahwa manusia harus punya etika lingkungan yang menghimbau dan mengajak untuk kembali ke etika masyarakat adat yang masih relevan dengan perkembangan zaman.

\section{Penutup}

Ruwat Petirtaan Jolotundo memberikan dampak baik terhadap keberadaan sumber mata air, kelestarian flora dan fauna. Peserta Ruwat dan masyarakat Desa Seloliman menjadi lebih sadar akan pentingnya menjaga sumber mata air, flora dan fauna yang ada. Hasilnya kondisi sumber air Jolotundo masih lestari, begitu pula dengan flora dan fauna di Kawasan Jolotundo. Ruwat petirtaan jolotundo perlu dijaga dan terus dilaksanakan sebagai upaya menjaga kelestarian alam dan tradisi budaya lokal. Anak-anak perlu diberi ruang lebih banyak sebagai generasi penerus yang akan menjaga kelestarian Jolotundo dan sekitarnya. Penelitian ini bisa dikembangkan pada tema urgensi Ruwat atau kearifan lokal sebagai alternatif metode dalam menjaga lingkungan hidup.

\section{Daftar Pustaka}

Achal, V., Mukherjee, A., \& Zhang, Q. (2016). Unearthing ecological wisdom from natural habitats and its ramifications on development of biocement and sustainable cities. Landscape and Urban Planning, 155, 61-68. https: //doi.org/10.1016/j.landurbplan.2016 .04 .013

Anggraini, P. (2018). Mitos Sebagai Upaya Pelestarian Lingkungan (Sebuah Kajian Kritik Lingkungan Dalam Novel Sebuah Wilayah Yang Tidak Ada Dalam Google Earth Karya Pandu Hamzah). Prosiding Seminar Nasional Bahasa dan Sastra halaman 313-323.

Badan Pusat Statistik Indonesia. (2020). Statistik Lingkungan Hidup Indonesia. Jakarta: Badan Pusat Statistik Indonesia.

Badan Pusat Statistik Kabupaten Mojokerto. (2018). Kecamatan Trawas dalam Angka. Mojoketo: BPS Kabupaten Mojokerto.

Daniah. (2018). Kearifan Lokal (Local 
Wisdom) Sebagai Basis Pendidikan Karakter. UIN Ar-Raniry Darussalam Banda Aceh.

Dharmawibawa, I. D. (2019). Kearifan Lokal Masyarakat Desa Seloto dalam Pengelolaan Sumberdaya Alam Di Danau Lebo. Jurnal Abdi Masyarakat, 1(1), 1-5.

Hariadi, U., Suratman, S., Gunawan, T., \& Armawi, A. (2020). Kearifan Lokal Komunitas Sebagai Modal Sosial alam Manajemen Bencana Alam. Majalah Geografi Indonesia, 33(2). https: //doi.org/10.22146/mgi.48548

Hartoyo, G. (2016). Ruwat Sumber Petirtaan Jolotundo. Surabaya: Yayasan Damar Abang Dawala.

Kakoty, S. (2018). Ecology, sustainability and traditional wisdom. Journal of Cleaner Production, 172, 32153224.

https://doi.org/10.1016/j.jclepro.2017 .11 .036

Kementerian Lingkungan Hidup dan Kehutanan Republik Indonesia. (2018). Indeks Kualitas Lingkungan Hidup Indonesia 2017. Jakarta: Kementerian Lingkungan Hidup dan Kehutanan Republik Indonesia.

Kristiyanto, E. N. (2017). Kedudukan Kearifan Lokal dan Peranan Masyarakat dalam Penataan Ruang di Daerah (Local Wisdom Position and Role of Society in Spatial Planning in the Region). Rechts Vinding, 6(2), 159-177.

Mardikantoro, H. B. (2016). Satuan Lingual Pengungkap Kearifan Lokal Dalam Pelestarian Lingkungan. Bahasa Dan Seni: Jurnal Bahasa, Sastra, Seni Dan Pengajarannya, 44(1), $\quad$ 047-059. https://doi.org/10.17977/um015v44i1 $2016 \mathrm{p} 047$

Maridi. (2015). Mengangkat Budaya dan Kearifan Lokal dalam Sistem Konservasi Tanah dan Air Using Culture and Local Wisdom in Soil and Water Conservation. Seminar Nasional XII Pendidikan Biologi UNS, Surakarta, 1, 20-39.

Mas'ud, A. (2019). Kesakralan Air Candi Jolotundo (Thesis). Surabaya:
Universitas Islam Negeri Sunan Ampel Surabaya.

Mawaddahni, S. (2017). Filosofi Hidup sebagai Wujud Kearifan Lokal Masyarakat Adat Kasepuhan Sinar Resmi. Local Wisdom: Jurnal IImiah Kajian Kearifan Lokal, 9(2). https://doi.org/10.26905/lw.v9i2.197 6

Nasution, P. (2018). "Wase Glee": Dari Kearifan Hingga Kenaifan Lokal Para Peramu Hasil Hutan di Aceh. Indonesian Journal of Anthropology, 2(1). https: //doi.org/10.24198/umbara.v2i1.156 72

Niman, E. M. (2019). Kearifan Lokal dan Upaya Pelestarian Lingkungan Alam. Jurnal Pendidikan Dan Kebudayaan Missio, 11(1), 91-106.

Pratiknyo, P. (2016). Teknologi Mineral. Jurnal IImu Kebumian Teknologi Mineral, 28(1), 27-39.

Puspita, I., Ibrahim, L., \& Hartono, D. (2016). Penurunan Kualitas Air Sungai Karang Anyar Kota Tarakan (Influence of The Behavior of Citizens Residing in Riverbanks to The Decrease of Water Quality in The River of Karang Anyar Tarakan City). Jurnal Manusia Dan Lingkungan, 23(2), 249-258.

Putri, F. R. D., Satria, A., \& Saharuddin, S. (2020). Pengelolaan berbasis Masyarakat Sasi Laut Folley dan Dinamika Pengelolaan Berbasis Masyarakat. Jurnal Pengelolaan Sumberdaya Alam Dan Lingkungan (Journal of Natural Resources and Environmental Management), 10(1), 111-123.

https://doi.org/10.29244/jpsl.10.1.11 $1-123$

Reza, M., \& Hidayati, A. N. (2017). Karifan Lokal Suku Sasak dalam Pengelolaan Sumber Daya Air Desa Lenek Daya, Kecamatan Aikmel Kabupaten Lombok Timur. Spectra, 15(30), 1-14.

Rosaliza, M. (2015). Wawancara, Sebuah Interaksi Komunikasi Dalam Penelitian Kualitatif. In Jurnal IImu Budaya (Vol. 11, Issue 2, pp. 71- 
79). //doi.org/10.31849/jib.v11i2.1099

Schwann, A. (2018). Ecological wisdom: Reclaiming the cultural landscape of the Okanagan Valley. Journal of Urban Management, 7(3), 172-180. https:

//doi.org/10.1016/j.jum.2018.05.004

Seprianto, D., Suminar, P., \& Nopianti, H. (2019). Bukit Larangan: Prinsip KonservasI Masyarakat Berbasis Kearifan Lokal (Studi Kasus Desa Aur Gading Kecamatan Kerkap, Kabupaten Bengkulu Utara). Jurnal Sosiologi Nusantara, 3(1), 37-45. https: //doi.org/10.33369/jsn.3.1.3745

Sinapoy, M. S. (2018). Kearifan Lokal Masyarakat Adat Suku Moronene dalam Perlindungan dan Pengelolaan Lingkungan Hidup. Halu Oleo Law Review, 2(2), 513. https://doi.org/10.33561/holrev.v2i2. 4513

Sudarsana, I. K. (2017). Konsep Pelestarian Lingkungan Dalam Upacara Tumpek Wariga Sebagai Media Pendidikan Bagi Masyarakat Hindu Bali. Religious: Jurnal Studi Agama-Agama Dan Lintas Budaya, 2(1), $\quad 1 . \quad$ https: //doi.org/10.15575/rjsalb.v2i1.1934

Sufia, R., Sumarmi, \& Amirudin, A. (2016). Kearifan Lokal Dalam Melestarikan Lingkungan Hidup (Studi Kasus Masyarakat Adat Desa Kemiren Kecamatan Glagah Kabupaten Banyuwangi). Jurnal Pendidikan: Teori, Penelitian, Dan Pengembangan, 1(4), 726-731. https://doi.org/10.17977/JP.V1/4.623 4

Surata, I., Gata, I., \& Sudiana, I. (2015). Studi Etnobotanik Tanaman Upacara Hindu Bali sebagai Upaya Pelestarian Kearifan Lokal. Jurnal Kajian Bali (Journal of Bali Studies), 5(2), 265-284.

Suyatman, U. (2018). Teologi Lingkungan dalam Kearifan Lokal Masyarakat Sunda. Al-Tsaqafa: Jurnal IImiah Peradaban Islam, 15(1), 77-88. https: $\quad$ //doi.org/10.15575/al- tsaqafa.v15i1.3037

Swandi, I. W. (2017). Kearifan lokal Bali untuk pelestarian alam: Kajian wacana kartun-kartun majalah "BogBog." Jurnal Kajian Bali (Journal of Bali Studies), 7(2), 229. https://doi.org/10.24843/jkb.2017.v0 7.i02.p12

Syarif, E. (2017). Pengelolaan Lingkungan dalam Perspektif Kearifan Lokal Masyarakat Adat Karampuang Kabupaten Sinjai Sulawesi Selatan. Jurnal Sainsmat $\mathrm{VI}(2), 49-56$.

Thamrin, H. (2017). Aspek kearifan lokal dalam pelestarian lingkungan. AlFikra, 16(2).

Uar, N. D., Murti, S. H., \& Hadisusanto, S. (2016). Kerusakan lingkungan akibat aktivitas manusia pada ekosistem terumbu karang. Majalah Geografi Indonesia 8(3), 6-10.

Ulum, M., Hardiyati, K., \& Irfan, I. (2019). Lombe, sebagai upaya konservasi kerbau Pulau Kangean Kabupaten Sumenep. Jurnal Pendidikan Geografi, 24(1), 11-10. https: //doi.org/10.17977/um017v24i12019 p001

Vitasurya, V. R. (2016). Local Wisdom for Sustainable Development of Rural Tourism, Case on Kalibiru and Lopati Village, Province of Daerah Istimewa Yogyakarta. Procedia Social and Behavioral Sciences, 216(October 2015), 97-108. https: //doi.org/10.1016/j.sbspro.2015.12.0 14

Zhang, L., Yang, Z., Voinov, A., \& Gao, S. (2016). Nature-inspired stormwater management practice: The ecological wisdom underlying the Tuanchen drainage system in Beijing, China and its contemporary relevance. Landscape and Urban Planning, 155, 11-20. https: //doi.org/10.1016/j.landurbplan.2016 .06 .015 